\title{
Evaluations of Information Assymetry
}

\author{
Tsvetkov Victor Yakovlevich ${ }^{1}$ \\ ${ }^{1}$ Moscow State University of Radio Engineering, Electronics and Automation (MSTU MIREA), Prospect \\ Vernadskogo, Moscow, Russia \\ Correspondence: Tsvetkov Victor Yakovlevich, Professor, doctor of technical science, Moscow State University \\ of Radio Engineering, Electronics and Automation (MSTU MIREA), 119454, 78, Prospect Vernadskogo, \\ Moscow, Russia.
}

Received: November 27, 2014

Accepted: December 13, 2014 Online Published: May 30, 2015

doi:10.5539/mas.v9n6p243

URL: http://dx.doi.org/10.5539/mas.v9n6p243

\begin{abstract}
This paper is the analytical work describing evaluation methods of some types of information asymmetry. Duality of possible evaluations of information asymmetry is shown: in comparison to the similar object and the set goal. The types of informational situations where asymmetry occurs are described. The types of information asymmetry are described: on information, on information exchange, on information interaction, on information situation, on information flow. The ideas of the general state of object and the informational state of object are described. The difference between them is shown. The concept of awareness of the object or subject is given. The qualitative and quantitative evaluation methods of information asymmetry are given. It is shown that the asymmetry is possible not only on the state of object, but also on information flow coming to the objects. The limitations and possible negative consequences of qualitative estimates are shown. These analytical terms allow defining the informational characteristics of objects such as: "information superiority"; "adequacy of resource provision" or "lack of resource provision"; "possibility of achieving goal" or "failure of achieving goal"; "information asymmetry on resources" or "information asymmetry on the situation." The distinction between formal and actual information asymmetry is given. The idea of natural and artificial information asymmetry is noted. The idea of attributive and procedural information asymmetry is given. Recommendations to address the information asymmetry are given.
\end{abstract}

Keywords: information, informational situation, information asymmetry, information flows, informing, information interaction, informational state, information superiority, resource provision, achieving the goal

\section{Introduction}

Information is one of the most important types of economic resources. However, in real practice only a limited mass of information is available for each economic agent. Completeness of information is a sign of real economic and managerial situations. Completeness of information may affect the conditions and features of markets operations, causing additional transaction costs for economic agents. Asymmetric information is a special type of completeness of information which causes the greatest impact on market activity. The asymmetry of information causes the potential for abuse by one of the transaction parties because of the lack of awareness of the counterparty. The asymmetry of information, unlike completeness, leads to a sharp reduction in social welfare. An important reason for the decreasing of the competitive intensity and the acquisition of monopoly power in the markets is the completeness and asymmetry of information. Asymmetry of information causes a special situation, which is called information asymmetry. Information asymmetry is an informational situation where one of the parties in the market or the information interaction has better information than the other (Hughes, J., Liu, J., \& Liu, J., 2007; Lambert, R., Leuz, C., \& Verrecchia, R., 2012). The consequence of the information asymmetry in the market is the phenomenon of fact of quality degradation of a good in the market, which is called adverse selection (Greenwald, B., 1986). Initially, information asymmetry was explained by different awareness of interacting subjects (Pavlou, P., Liang, H., \& Xue, Y., 2007). In practice other types of asymmetry are identified (Sufi, A., 2007; Aboody, D., \& Lev, B., 2000). As a rule, information asymmetry is associated with studies of Akerdof G. The most famous article by Akerlof G. which brought him the Nobel Prize in 2001 was "The Market for Lemons" (Akerlof, G., 1970). "Lemon law" is the law according to which the car seller obligates to repair, replace, or refund the money for the car with identified defects free of charge. "Lemons" refer to all goods in which the buyer cannot be sure. For example, there is the word "satin" in 
everyday speech in Moldova. The wine is called this way if it was in places where it might be diluted or replaced. From this point of view, it is obvious the wine that the owner has made for himself, excluded from trade transactions, cannot be such "satin".

Information asymmetry occurs during scientific research, particularly in extraction of knowledge (Ivannikov, A., Kulagin, V., Mordvinov, V., et al., 2008). This appears in obtaining plausible but not true knowledge. Thus, information asymmetry is an objective reality arising in the processes of interaction and relations in practice. It makes it relevant to study situations that involve information asymmetry. And it makes it necessary to develop evaluation methods of information asymmetry, and the development of evaluation methods of information parameters such as: information superiority, resource provision, the possibility of achieving the goals, etc.

\section{Methodology}

Evaluation methodology is based on the introduction of basic concepts and conducting qualitative and quantitative evaluations associated with these concepts. That is a method is based on the synthesis of qualitative and quantitative analysis. The following basic concepts in the analysis of information asymmetry are applied: "information situation" (Tsvetkov, V., 2012), "information state", "general state", "object" or "subject" of evaluation, "awareness". Information asymmetry is evaluated to the object or subject equally (Soloviev, I., 2013). Information situation is an information model describing the information environment (Hair, J., Bush, R., \& Ortinau, D., 2003) of the object of analysis or its local information environment (Ozherelieva, T., 2014a). This is a kind of a passive information model, in which the analyzed object or subject are located.

It is necessary to distinguish between the concepts of "information state" of the object or subject and "general state" of the object or subject. Information state of the object or subject is defined as a set of parameters for particular informational situation. Information state can be considered as an information model evaluated relative to another information model, which is an informational situation. Information state is a comparative characteristic. In reality, it is evaluated only on characteristics of information mainly on the quantity and quality of information resources. Information state is evaluated by a set of parameters that are included in the description of the informational situation. There can be a lot of information states for one informational situation. Information state can be evaluated relative another object in a given informational situation, or relative to the set target of the object.

The general state of the object or subject is determined by a complete set of parameters, including those that are not included in the description of the informational situation. The general state of the object or subject is described by a larger number of parameters compared with the number of parameters describing the information state. These are characteristics among the parameters that describe the general state: informational, financial, energy, and other resources. Later on we will use the term "information" for the reduction, which will denote information resources when analyzing of the asymmetry.

It is also necessary to distinguish between the notion of "actual information state" and "essential information state" which is needed to achieve a goal or solve a problem. This inequality of "actual" and "essential" information states indicates the presence of information asymmetry. "Awareness" in the absolute evaluation represents the actual amount and quality of information resources, which the object or the subject of evaluation has. Such awareness characterizes the actual information state. Awareness in the relative evaluation is defined as the possession of useful and qualitative information necessary to achieve the goals. Such awareness characterizes the necessary information state. Awareness in relative evaluation can be determined by comparison of information resources of two objects.

Informational situations are divided into static and dynamic (Tsvetkov, V., \& Shorygin S., 2014). Static information situation is described by the parameters that do not vary over time. Dynamic information situation is described by the parameters that vary over time, and for which the dependency of the varying from time is known. Accordingly, information asymmetries will also be static or dynamic. Type of information asymmetry will be determined by the kind of informational situation that leads to this information asymmetry.

\section{Results}

Consider the information situation in which asymmetry may appear. To indicate the inequality of states a mathematical sign "inequality" can be used. This allows creating a simple description of information asymmetry on awareness.

$$
\begin{gathered}
A(I)>B(I) \\
A(I)<B(I)
\end{gathered}
$$


Expressions (1) and (2) determine the information asymmetry between the marked $A, B$ objects or subjects on awareness (I). This informational situation is called the situation a situation of "inequality in awareness." Corresponding information asymmetry will be called the information "asymmetry in awareness." Expression (1) is interpreted as follows. The actual awareness of the object $A$ is greater than the awareness of the object $B$. Expression (2) is interpreted with the opposite meaning. Awareness of the object $B$ is greater than awareness of the object $A$. The expression (1) points the information superiority of the object $A$ over the object $B$. The expression (2) points the information superiority of the object $B$ over the object $A$ (Tikhonov, A., Ivannikov, A., \& Soloviev, I., et al., 2010b).

Expressions (1) and (2) characterize the static informational situations. This asymmetry is an attribute, as it characterizes certain properties of the informational situation. We define the coefficient of awareness $K_{I}$ as

$$
\mathrm{K}_{\mathrm{I}}=\mathrm{I}_{\mathrm{F}} / \mathrm{I}_{\mathrm{T}}
$$

Where $I_{T}$ - the amount of information necessary to achieve the goal, $I_{F}$ - the amount of information that is actually had by the object or subject. The amount of information is denoted as content component and not the information volume. This coefficient has a value between 0 and 1 .

It should be noted that the comparative evaluation of the asymmetry and informational situation has two criteria. In the interpretation of the expressions (1) and (2) a comparison between the objects $A$ and $B$ were made. Such a comparison can be defined as comparison of the objects. If there are not two objects, but $\mathrm{N}$, then $\mathrm{N}$ paired comparisons can be made; and using the methods of any comparison theory, for example the theory of preferences (Tsvetkov, V., 2004), to construct a system of preference for $\mathrm{N}$ objects, and to rank them according to the selected criteria. This determines the possibility of comparison of the objects for any number of objects.

The second option of comparison is associated with the selection of the object and goal, which he should achieve. In this case, the object $A$ can be considered as the object of analysis, and the object $B$ as the target. Such comparison can be defined as a comparison of the target. Expression (1) points the possibility of achieving the goal by the object $A$ on the basis of its available resources. Expression (2), when comparison of the target, points about the impossibility of achieving the goal by the object $A$ on the basis of its available resources. If there are not two objects, but $\mathrm{N}$, then $\mathrm{N}$ paired comparisons can be made, and the table of objects able to reach the goal and the table of objects unable to reach the goal can be constructed. The second option of comparison provides a basis for decision making on changing the situation with providing resources of certain objects. The first option of comparison "on the object" allows evaluating the competitiveness of a given set of objects to each other in the market or in a situation of interaction.

Informational situation in which the object or subject receives information flows from various external sources is possible. This situation can also lead to information asymmetry. It is possible in the presence of different information resources and flows of different intensity. This situation is called flowing informational situation. Information flows of different intensity and quality change information state of the objects.

$$
\mathrm{F}_{\mathrm{S} 1} \rightarrow \mathrm{I}_{\mathrm{B}}>\mathrm{F}_{\mathrm{S} 2} \rightarrow \mathrm{I}_{\mathrm{A}}
$$

Expression (4) is interpreted as follows. Information flow $F_{S I}$ directed to $B$ exceeds information flow $F_{S 2}$ directed to $A$ which create information asymmetry on the incoming information flows. Such information asymmetry will be called the information "asymmetry on awareness" or the information "asymmetry on external information flows". Accordingly, such informational situation is called flowing informational situation. This information asymmetry is procedural, as it characterizes the process. Informational situation described with the aid of (4) is also procedural or dynamic. Determine the relative coefficient of the information flow $F_{F B}$ to the source $B$ as

$$
\mathrm{K}_{\mathrm{FB}}=\mathrm{F}_{\mathrm{S} 1} /\left(\mathrm{F}_{\mathrm{S} 1}+\mathrm{F}_{\mathrm{S} 2}\right)
$$

Determine the relative coefficient of information flow $\mathrm{K}_{\mathrm{FA}}$ to the source $\mathrm{A}$ as

$$
\mathrm{K}_{\mathrm{FA}}=\mathrm{F}_{\mathrm{S} 2} /\left(\mathrm{F}_{\mathrm{S} 1}+\mathrm{F}_{\mathrm{S} 2}\right)
$$

The relative coefficients of information flow $K_{F A}$ and $K_{F B}$ have values between 0 and 1. A feature of flowing informational situation shown in the expression (4) is that the inequality sign can be replaced by an equal sign. In this case it is information symmetry on flows.

A special case of asymmetry of information may serve asymmetry associated with the mutual exchange of information between two objects or subjects. Such informational situation arises in the presence of the mutual countervailing information flows. Flows perform the passive role of informing objects. Such information asymmetry is procedural, as it is caused by the process. Information exchange changes the number of the 
information objects, and may also create asymmetry.

$$
\mathrm{F}_{\mathrm{A}}: \mathrm{I}_{\mathrm{A}} \rightarrow \mathrm{I}_{\mathrm{B}}>\mathrm{F}_{\mathrm{B}}: \mathrm{I}_{\mathrm{B}} \rightarrow \mathrm{I}_{\mathrm{A}}
$$

Expression (7) is interpreted as follows. Information flow $\mathrm{F}_{\mathrm{A}}$, in the direction from $\mathrm{A}$ to $\mathrm{B}$ exceeds information flow in the direction $F_{B}$ from $B$ to $A$, which results in asymmetry information. This information asymmetry is called the "information asymmetry on information exchange". Determine the coefficient of information exchange $\mathrm{KA}_{\mathrm{EXC}}$ from the source $\mathrm{A}$ to the source $\mathrm{B}$ as

$$
\mathrm{KA}_{\mathrm{EXC}}=\mathrm{F}_{\mathrm{A}} /\left(\mathrm{F}_{\mathrm{B}}+\mathrm{F}_{\mathrm{A}}\right)
$$

In the opposite direction

$$
\mathrm{KB}_{\mathrm{EXC}}=\mathrm{F}_{\mathrm{B}} /\left(\mathrm{F}_{\mathrm{B}}+\mathrm{F}_{\mathrm{A}}\right)
$$

Here $F_{A}$ - the intensity of flow from $A$ to $B, F_{B}$ - the intensity of flow from $B$ to $A$. The coefficients $K A_{E X C}$ and $K B_{E X C}$ can be compared with each other. They are normalized between 0 and 1 .

Flowing informational situation changes awareness of the object and can lead to asymmetry. At the same time, not every flowing informational situation leads to information asymmetry. It depends on the actual level of awareness, determined by expressions (1) and (2). For example, if there is a semantic gap (Tsvetkov, V., 2013), the direction of flow can either reduce or increase the semantic gap. Consequently, flowing informational situation can serve as a means reducing asymmetry. The semantic gap is an example of information asymmetry on awareness.

Asymmetry that arises in the course of information interaction is possible (Shedroff, N., 1999). Interaction, unlike the exchange of information, is an active process. Exchange of information changes awareness of the objects and only affects the information state. Interaction effects on the general state of the object. The situation of information interaction is characterized by flows that are aimed at changing the general state of the object. Such situation is called an information situation of interaction.

$$
\operatorname{Int}_{\mathrm{A}}: \mathrm{I}_{\mathrm{A}} \rightarrow \mathrm{I}_{\mathrm{B}}>\operatorname{Int}_{\mathrm{B}}: \mathrm{I}_{\mathrm{B}} \rightarrow \mathrm{I}_{\mathrm{A}}
$$

Expression (10) is interpreted as follows. Informational influence $\mathrm{Int}_{\mathrm{A}}$ of the object A exceeds informational influence $\mathrm{Int}_{\mathrm{B}}$ of the object B, which causes information asymmetry. Such information asymmetry will be called the information "asymmetry on the interaction". This information asymmetry is procedural, as it is caused by the process. However, this informational situation can be balanced and do not lead to asymmetry. In this case we suggest information consistency or information compliance of the objects A and B (Mikkelsen, G., \& Aasly, J., 2001). Determine the coefficient of information interaction $K_{\mathrm{INT}}$ from the source $A$ to the source $B$ as

$$
\mathrm{KA}_{\mathrm{INT}}=\operatorname{Int}_{\mathrm{A}} /\left(\mathrm{Int}_{\mathrm{A}}+\mathrm{Int}_{\mathrm{B}}\right)
$$

A special case of expression (10) is a situation where $B$ denotes the goal. In this case, we have two possible situations

$$
\begin{aligned}
& \operatorname{Int}_{\mathrm{A}}: \mathrm{I}_{\mathrm{A}} \rightarrow \mathrm{I}_{\mathrm{B}} \geq \operatorname{Int}_{\mathrm{B}}: \\
& \operatorname{Int}_{\mathrm{A}}: \mathrm{I}_{\mathrm{A}} \rightarrow \mathrm{I}_{\mathrm{B}}<\operatorname{Int}_{\mathrm{B}}:
\end{aligned}
$$

Expression (12) is interpreted as follows. Informational influence $I n t_{A}$ of the object $A$ is enough to achieve the goal.

Expression (13) is interpreted as follows. Informational influence $\operatorname{Int}_{A}$ of the object $A$ is not enough to achieve the goal $B$, which causes information asymmetry "on the goal".

On formal features, the expressions (12) and (13) describe the asymmetry, but actually asymmetry occurs only for the case (13).

This suggests the existence of formal and actual asymmetry. Formal asymmetry (12) does not worsen the state of goal achievement. Excess of resources is not a critical obstacle to the actions of the object $A$. The actual asymmetry (13) is critical. It fails to achieve the goal, and therefore requires action of the resource provision of the object $B$ or on its awareness.

It is possible that the information impacts, in which different objects independently affects $A$ and $B$. It can cause information asymmetry. Such situation is called "informational situation of independent impacts". Analytical model of asymmetry with the external impacts $(E x A)$ on the objects to change their states is the following.

$$
\mathrm{ExA}_{1} \rightarrow \mathrm{I}_{\mathrm{B}}>\mathrm{ExA}_{2} \rightarrow \mathrm{I}_{\mathrm{A}}
$$


Expression (14) is interpreted as follows: the external impact $E x A_{1}$ on the subject $B$ which causes its awareness $I_{B}$ and exceeds the external impact $E x A_{2}$ on the subject $A$ which causes its awareness $I_{A}$. This creates information asymmetry on external impacts and information superiority (Tikhonov, A., Ivannikov, A., Soloviev, I., et al., $2010 \mathrm{~b}$ ) of the object $B$ over the object $A$. This information asymmetry is procedural, as it is caused by the process. Expression (14) can signal that the resource provision of the object $B$ exceeds the resource provision of the object $A$.

It should be noted that the informational situation described by the expression (10) and (14) can be characterized by changing the inequality sign by the equality sign. In this case there will be information symmetry. Besides, the inequality sign in expressions (10) and (14) can be directed in the opposite side. This also characterizes asymmetry.

Determine the coefficient of relative information impact $K A_{A}$ on the object $A$ as

$$
\mathrm{KA}_{\mathrm{A}}=\mathrm{ExA}_{2} /\left(\mathrm{ExA}_{2}+\mathrm{ExA}_{1}\right)
$$

Determine the coefficient of relative information impact $\mathrm{KB}_{\mathrm{A}}$ on the object $\mathrm{B}$ as

$$
\mathrm{KB}_{\mathrm{A}}=\mathrm{ExA}_{1} /\left(\mathrm{ExA}_{2}+\mathrm{ExA}_{1}\right)
$$

Information asymmetry that occurs in the situation analysis is possible. Suppose that the object $\mathrm{A}$ is in a situation $\mathrm{S}_{1}$, which is characterized by a set of parameters $\mathrm{P}_{1}$. The object B is in a situation $\mathrm{S}_{2}$, which is characterized by a set of parameters $\mathrm{P}_{2}$. Using the theory of preferences (Tsvetkov, V., 2004) or other criteria (Saaty, T., 2008) it can be concluded (conditionally) that $P_{1}$ is preferable to $P_{1}$

$$
\mathrm{P}_{1} \Rightarrow \mathrm{P}_{2}
$$

Expression (17) points that $S_{I}$ is preferable to $S_{2}$, which implies the presence of asymmetry in situations between $A$ and $B$. Such information asymmetry will be called the information "asymmetry on the preference". It signals that the object $A$ is more competitive compared with the object $B$. Another criterion of comparison may be the criterion of "the wealth of information resources" (Tikhonov, A., Ivannikov, A., Soloviev, I., et al., 2010a). There may be other methods of evaluating informational situation that allow evaluating the symmetry or asymmetry of the situation on information parameters (Shevchenko S. V., 2014). If $B$ is assumed as the target, which the object $A$ should reach, then expression (17) points that the object $A$ is in the situation that allow achieving the goal $B$. When replacing the direction of preference in expression (17) is reversed, variant interpretation of the expression (17) is possible. The object $A$ is in a situation that does not allow reaching the goal $B$.

\section{Discussion}

Information asymmetry is a relative characteristic. Hereby, duality of comparison between similar objects and between the object and its goal is possible. The considered methods include qualitative and quantitative analysis.

Expressions (1), (2), (4), (7), (10), (12-14), and (17) are based on the qualitative and quantitative evaluations. They require expert evaluations. Hereby, the evaluations are for the most part of a comparative nature. This means that when the number of parameters used for evaluation changes, the result may vary. Evaluations of this kind have the truth domain only on the group of compared parameters.

Expressions (3), (5), (6), (8), (9), (11), (15), and (16) use quantitative measures, which gives the possibility of obtaining the objective quantitative evaluation. A feature of these expressions is that all quantitative evaluations are normalized between 0 and 1 . This creates the conditions not only for evaluation, but for the application of methods of statistical analysis and methods of probability theory to evaluate the hypotheses of the first and second kind. However, the weight or importance of quantitative evaluations (3), (5), (6), (8), (9), (11), (15), and (16) depend on quality evaluations obtained in expressions (1), (2), (4), (7), (10), (12-14), and (17). The main problem of evaluation of information resources at their large numbers is this complexity (Ozherelieva, T., 2014b) The complexity of the evaluation of information resources or the complexity of the information situation (Tsvetkov, V., 2013b) leads to the need of simplification, which each expert makes the arbitrariness (Vagin, V., \& Fomina, M., 2014). This causes conditions for the distortion of the situation and obtaining plausible, but not a true evaluation. This qualitative evaluation can play a negative role in unfair or biased expert evaluation. This negative side of the qualitative expert evaluation is shown in the study (Tsyganov, V., 2014).

Information asymmetry can be natural and artificial. For example, in education, the natural information asymmetry is typical for all students. At school admission, they are in a state of information asymmetry between the knowledge necessary for professional work and those that they have. Flowing operation and information interaction between the teacher and the student eliminates this asymmetry. In this case, the awareness of asymmetry motivates the subject to eliminate information asymmetry. 


\section{Conclusion}

In this paper there is no distinction between the object and subject. This means that the results are applicable to evaluation of information asymmetry between both information systems and subjects. To evaluate information asymmetry and its elimination analytical expressions given in this paper are applied. However, the importance of information asymmetry, and the results of this study showing it goes beyond just information asymmetry as state of awareness which originally was considered by Akerlof (Akerlof, G., 1970). On the basis of these expressions and methods evaluation of competitiveness of the group of the objects with each other is possible. The results of the paper permit to obtain such a characterization as "information superiority" of the object over another object. The results of the study allow estimating the possibility of the achievement of the goal object "on the situation" or "on awareness." The results of the study suggest that there may be asymmetry not only on state, but also on information flows. This makes it possible to estimate this figure as a "resource provision of the object".

As the prospects for further studies, it should be noted the development of the proposed method based on the theory of preferences. More specifically, it is the use of matrices of paired comparisons of object properties or method for paired comparisons of integral position of the object in the information situation.

\section{Acknowledgments}

The author thanks Corresponding Member of RAS Savinykh V.P. for discussion of this article and tips to improve it.

\section{References}

Aboody, D., \& Lev, B. (2000). Information asymmetry, R\&D, and insider gains. The journal of Finance, 55(6), 2747-2766. http://dx.doi.org/10.1111/0022-1082.00305

Akerlof, G. (1970). The Market for 'Lemons': Quality Uncertainty and the Market Mechanism. Quarterly Journal of Economics (The MIT Press), 84(3), 488-500. http://dx.doi.org/10.2307/1879431

Greenwald, B. (1986). Adverse selection in the labour market. The Review of Economic Studies, 53(3), 325-347. http://dx.doi.org/10.2307/2297632

Hair, J., Bush, R., \& Ortinau, D. (2003). Marketing research: Within a changing information environment. Richard d Irwin.

Hughes, J., Liu J., \& Liu, J. (2007). Information asymmetry, diversification, and cost of capital. The Accounting Review, 82(3), 705-729. http://dx.doi.org/10.2308/accr.2007.82.3.705

Ivannikov, A., Kulagin, V., \& Mordvinov, V. et al. (2008). Extraction of knowledge for the formation of information resources. Moscow: Informatika.

Lambert, R., Leuz, C., \& Verrecchia, R. (2012). Information asymmetry, information precision, and the cost of capital. Review of Finance, 16(1), 1-29. http://dx.doi.org/10.1093/rof/rfr014

Mikkelsen, G., \& Aasly, J. (2001). Concordance of information in parallel electronic and paper based patient records. International journal of medical informatics, 63(3), 123-131. http://dx.doi.org/10.1016/S1386-5056(01)00152-6

Ozherelieva, T. (2014a). On the relation of the concepts of information space, information field, information environment and semantic environment. International journal of applied and fundamental research, 10, 21-24.

Ozherelieva, T. (2014b). Complexity of information resources. Sovremennye naukoemkie tehnologii. Modern high technologies, 80-85.

Pavlou, P., Liang, H., \& Xue, Y. (2007). Understanding and mitigating uncertainty in online exchange relationships: a principal-agent perspective. MIS quarterly, 105-136.

Saaty, T. (2008). Decision making with the analytic hierarchy process. International journal of services sciences, 1(1), 83-98. http://dx.doi.org/10.1504/IJSSCI.2008.017590

Shedroff, N. (1999). Information interaction design: A unified field theory of design. Information design, 267-292.

Shevchenko, S. (2014). On the formation of the generalized dominance criterion based on fuzzy logic. Obrazovatelnie resursy I technologii. Educational resources and technologies, 2, 86-90.

Soloviev, V. (2013). About the origin and content of the term «InfoSphere». Perspektivy nauki i obrazovanija. Perspectives of Education and Science, 5, 14-18. 
Sufi, A. (2007). Information asymmetry and financing arrangements: Evidence from syndicated loans. The Journal of Finance, 62(2), 629-668. http://dx.doi.org/10.1111/j.1540-6261.2007.01219.x

Tikhonov, A., Ivannikov, A., \& Soloviev, I., et al. (2010a). Osnovy upravleniia slozhnoi organizatsionno-tekhnicheskoi sistemoi. Informatsionnyi aspect. Basics of management of complex technical-organizational system. Information aspect. Moscow: MaksPress.

Tikhonov, A., Ivannikov, A., \& Soloviev, I., et al. (2010b). Kontseptsiia setetsentricheskogo upravleniia slozhnoi organizatsionno-tekhnicheskoi sistemoi. Concept of network-centric management of complex technical-organizational system.

Tsvetkov, V. (2004). Basics of preference theory. Moscow: MaksPress.

Tsvetkov, V. (2012). Information Situation and Information Position as a Management Tool. European Researcher, 12-1(36), 2166- 2170.

Tsvetkov, V. (2013a). Information Interaction as a Mechanism of Semantic Gap Elimination. European Researcher, 4-1(45), 782-786.

Tsvetkov, V. (2013b). Complexity Index. European Journal of Technology and Design, 1(1), 64-69. http://dx.doi.org/10.13187/ejtd.2013.1.64

Tsvetkov, V., \& Shorygin, S. (2014). Dynamic information situation to overcome missile defense. Herald of MSTU MIREA, 3(4), 85-100.

Tsyganov, V. (2014). Technology preparation of revolution: models and methods of falsification of history. Obrazovatelnie resursy I technologii. Educational resources and technologies, 4, 42-49.

Vagin, V., \& Fomina, M. (2014). The argument in the inductive formation of concepts. Obrazovatelnie resursy I technologii. Educational resources and technologies, 2, 34-39.

\section{Copyrights}

Copyright for this article is retained by the author(s), with first publication rights granted to the journal.

This is an open-access article distributed under the terms and conditions of the Creative Commons Attribution license (http://creativecommons.org/licenses/by/3.0/). 